\title{
Solar Power Harnessing For Led Application Using Interleaved Boost Converter
}

\author{
Sri Vathsa $\mathrm{K}^{1}$, Dr. P Usha ${ }^{2}$ \\ ${ }^{1}$ PE, M.Tech Dept of Electrical Engg. DSCE, Bangalore-78 \\ ${ }^{2}$ Professor Dept of Electrical Engg. DSCE, Bangalore-78
}

\begin{abstract}
The ever increasing demand for the Electrical energy has made the mankind to turn towards renewable energy sources. Photovoltaic $(P V)$ is one of the renewable energy source. For effective and efficient utilization of the SPV panel a DC-DC converter interface required. The problem in using high frequency converter interface is the resultant high frequency ripple interaction with the SPV system. In this work, an interleaved boost converter (IBC) is considered to reduce the ripple. Our finding is that IBC fed by a SPV panel reduces this ripple to a greater extent. IBC also has a faster transient response as compared to conventional boost converters with reduced ripple contents. The advanced PWM techniques are used to decrease the ripple current to minimum value and to increases the efficiency of the system. The performance have been analyzed with the help of MATLAB/Simulink. The simulation result shows that IBC converter reduces the ripple current and increases the efficiency of the system.
\end{abstract}

Keywords: Closed loop control, Interleaved boost converter, MPPT circuit, PWM, Solar Panel,

\section{Introduction}

In the present time, there has been a huge demand for power because of the rapid industrial growth, along with an increase in residential loads. As it is necessary to meet these increasing power demands, and since non-renewable energy resources such as fossil fuels are quickly being depleted, alternative, renewable energy resources such as wind energy, solar energy, hydroelectric energy, and bio-mass energy have become major areas of research. Solar energy is one of the most reliable sustainable energy sources and does not require waste management nor pollute the environment. In order to boost the voltage output from PV panels, a boost converter is employed. The basic converter belonging to the family of DC-DC converter is Boost Converter.

The input power can be fed to this boost converter by more than one ways. Some of the regular methods includes batteries, solar cells and panels, rectifier and DC. DC conversion means increasing or decreasing the voltage level of the input DC voltage given to the converter. The other two are buck and buck boost derivatives. In recent times the use fuel cells and photovoltaic cells have received a wide usage in field of research to interface power electronic converter with energy source. These power source have usually quite low voltage output and require series connection of voltage booster to provide enough voltage output. The grid synchronized photo voltaic (PV) system are constructed from group of power point tracking (MPPT) cascaded by a grid synchronized inverter. [1] There are many boost converters which uses two or more converters for high voltage applications which produce higher output and reduce the output ripple [2]. Bin Gu et.al [3] presents a non isolated, high boost ratio fusion transformer to transfer DC-DC converter with application of low voltage applications.

The boost converters are used as power factor corrected pre regulators. The input inductance of the boost converter helps to control the current ripple and also reduces the electromagnetic emission. However the size of the inductor is proportional to the square of the peak current and for high voltage applications size is crucial Due to the usage of inductor in the boost converter the ripple current is introduced. Therefore the interleaving technique is used. An Interleaved Soft Switching Boost Converter (ISSBC) for a PV power generation system is proposed [4] The multistage conversions are used for high power applications. The multistage converter can defined as to see it as consisting of several power stages (converter "phases") with inputs and outputs connected in parallel and drive signals shifted to ensure uniform distribution over the switching period - this technique is called interleaving. This is employed to increase output power and to reduce the output ripple.

\subsection{Interleaved Boost Converter}

\section{Proposed Circuit}

The Boost converter belongs to DC DC topology in which the output voltage is greater than input voltage. It cannot be used for high power application due to the presence of ripple content which results in distortion of the output. The ripple is caused due to the rise and fall of inductor current. This can be eliminated by using the Interleaved Boost Converter which has many boost converter connected in parallel. The circuit 
diagram of Interleaved Boost converter is as shown in Fig 1. In an Interleaved Boost Converter, the two boost converter are operated in the same frequency but that the phase shift of $180^{\circ}$.

We know that the input current is the sum of the two current flowing through inductor. As they are operated at the $180^{\circ}$ shift, when they are added the ripple contents cancel each other, hence an Interleaved Boost Converter reduces the ripple content by the virtue of their design.

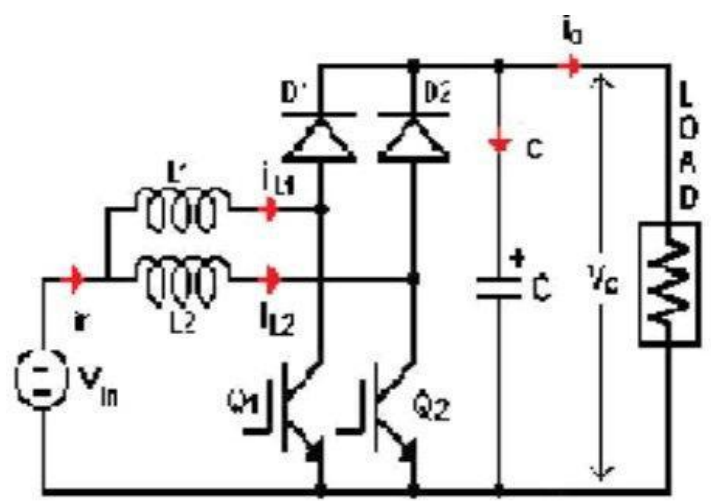

Fig 1 : Circuit Diagram of IBC

For the current to get equally divided the inductor should be chosen of equal value. Here the $\mathrm{L}$ is taken to be $0.713 \mathrm{mH}$. As two switches are used the Duty cycle D should be taken greater than 0.4 , if not the drive pulse may not able to turn $\mathrm{ON}$ a switch for a short time at which both the switches will be in OFF state. The Capacitor value is taken as $\mathrm{C}=4.79 \mu \mathrm{F}$ and switching frequency is set for the value $50 \mathrm{KHz}$.

\subsection{SOLAR CELL}

The energy from the sun is harnessed and then converted to electrical energy by PV cells. The converted energy will be in the form of DC current. Due to the inconsistency of the sun's radiation and other parameter the PV cell produce less voltage and generally lesser than the rated value. So to utilize the same for the real time load that power generated from the PV cell has to be boosted before feeding to the load, and hence they are fed to any DC-DC converter before connecting it to load, which in our case we are using Interleaved Boost Converter for boosting the input. Here we are using the 32 cell in Series parallel connection to make it an array. The above design is as simulated in the MATLAB Simulink

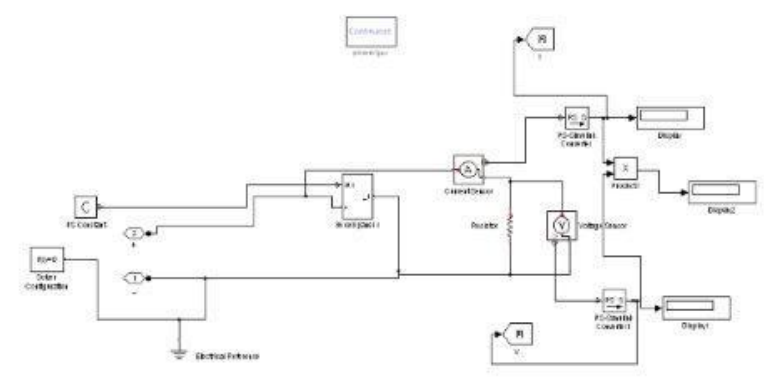

Fig 2 : PV Cell panel

\subsection{MPPT CIRCUIT}

In recent time all the solar panel no matter how advanced they are, the MPPT circuit is designed along with it for more reliable performance. The MPPT helps to get maximum power from the PV cell irrespective of change in environmental conditions. There are many algorithm which can be used, here we have used P\&O method (Perturb and Observe). When perturbation method is introduced in the system, it sense input voltage and current initially, then the PV cell is perturbed by adding a small increment till Maximum Power Point is achieved. The perturbation method is very simple to apply. However, it has some power losses due to the constant oscillation at the maximum power operating point 


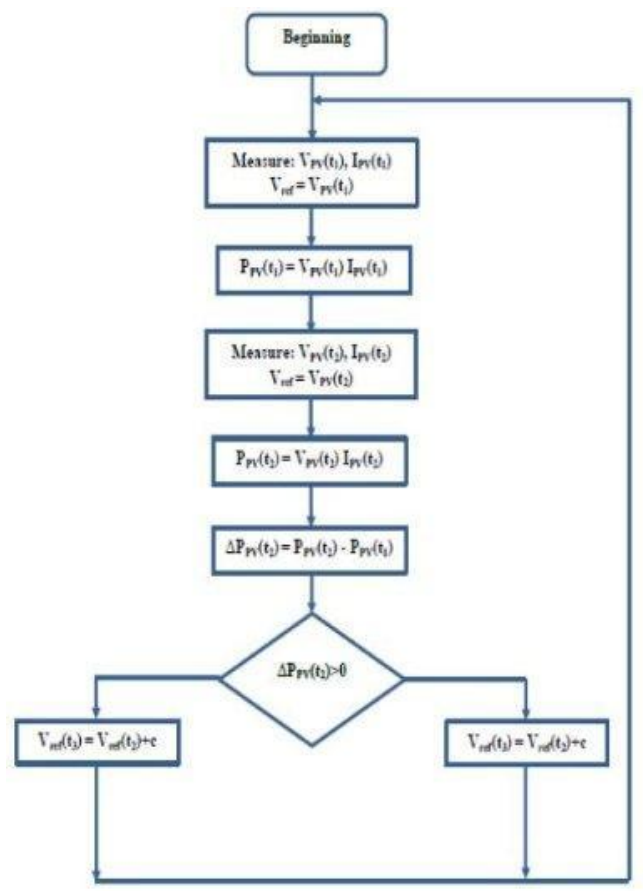

Fig 3. $\mathrm{P} \& \mathrm{O}$ algorithm chart

\subsection{CONTROL CIRCUIT DESIGN}

The control system which is used in the interleaved boost converter is PID controller which is used to reduce the oscillation in ripple current. They can be used either in open loop or closed loop modeling of DC-DC topology. The closed loop system is more accurate than the open loop system because they do not get disturbed in the presence of non linearities. The general block diagram of closed loop control are shown in fig 4

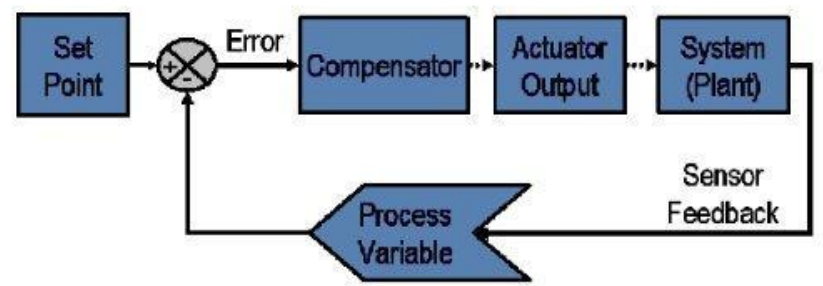

Fig 4 : Block diagram of closed loop system

A proportional-integral-derivative controller (PID controller) is a control loop feedback mechanism (controller) commonly used in industrial control systems. A PID controller continuously calculates an error value e $(t)$. e $(t)$ as the difference between a desired set point and a measured process variable and applies a correction based on proportional, integral, and derivative terms (sometimes denoted P, I, and D respectively) which give their name to the controller type. The PID controller is most widely adopted in industrial application due to its simple structure, easy to design and low cost.

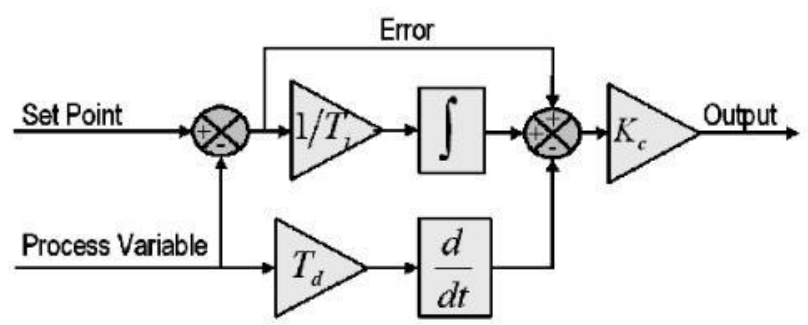

Fig 5. Block Diagram of PID Controller 
The controller output in this case is

$u(t)=K p \cdot e(t)+K i \int e(t) d t+K d e(d v / d t)$

A PID controller is called a PI, PD, P or I controller in the absence of the respective control actions. PI controllers are fairly common, since derivative action is sensitive to measurement noise, whereas the absence of an integral term may prevent the system from reaching its target value. The procedure of finding the controller parameter is called tuning.

\section{Signal Generator}

The Pulse Width Modulation (PWM) or Pulse Duration Modulation (PDM) is modulation technique used to encode the message into pulsing signal. Although it can be used to encode the information of transmission signal, its main use is to allow the control of power supplied to electrical drives, especially to internal loads such as motors. The PWM is one of the two principle algorithms used in photo voltaic solar battery charges the other is maximum power point tracking.

The term duty cycle describes the proportion of 'on' time to the regular interval or 'period' of time; a low duty cycle corresponds to low power, because the power is off for most of the time. Duty cycle is expressed in percent, $100 \%$ being fully on. The main advantage of PWM is that power loss in the switching devices is very low.We have analyzed for Single Pulse Width Modulation, The Single pulse Width Modulation signal is achieved by comparing the constant DC signal with the ramp voltage.

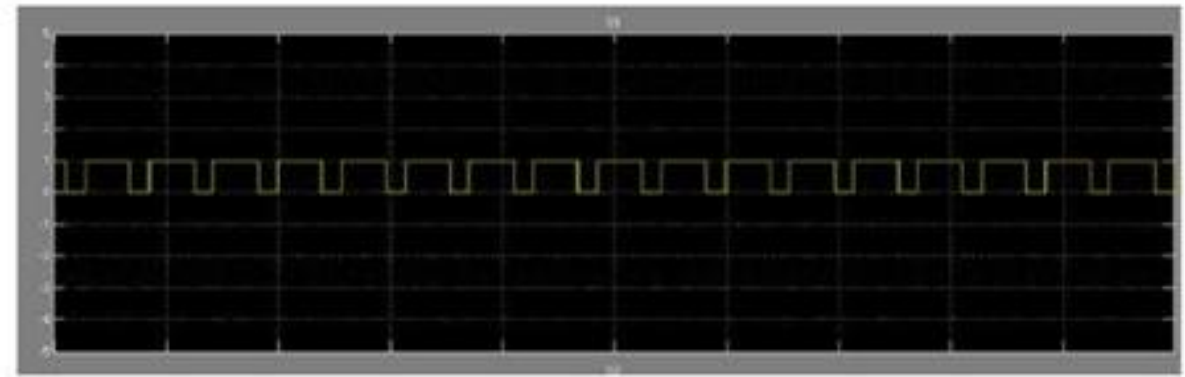

Fig 6 : Single Pulse Width Modulation Pulse

\section{Block Diagram}

The output of PV panel is fed to the MPPT circuit, which tracks the maximum power point by its controlling algorithm and fed to the main converter. The output is boosted sufficiently to drive the load and fed to the controller which regulates the voltage, allowing it to maintain constant voltage at the load terminal.

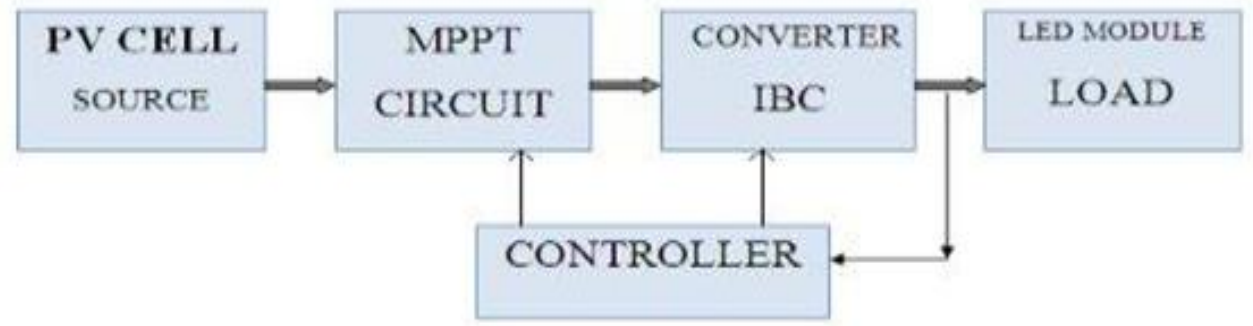

Fig 7 : Block Diagram of the proposed system

\section{Simulation Circuits And Waveform}

For Simulation we are MATLAB Simulink software. It is a block diagram environment for multi domain simulation and Model Based Design. Here the simulation results of Interleaved Boost Converter with MPPT and without MPPT are tabulated and its waveform are shown with the help of MATLAB SIMULINK 2010A 


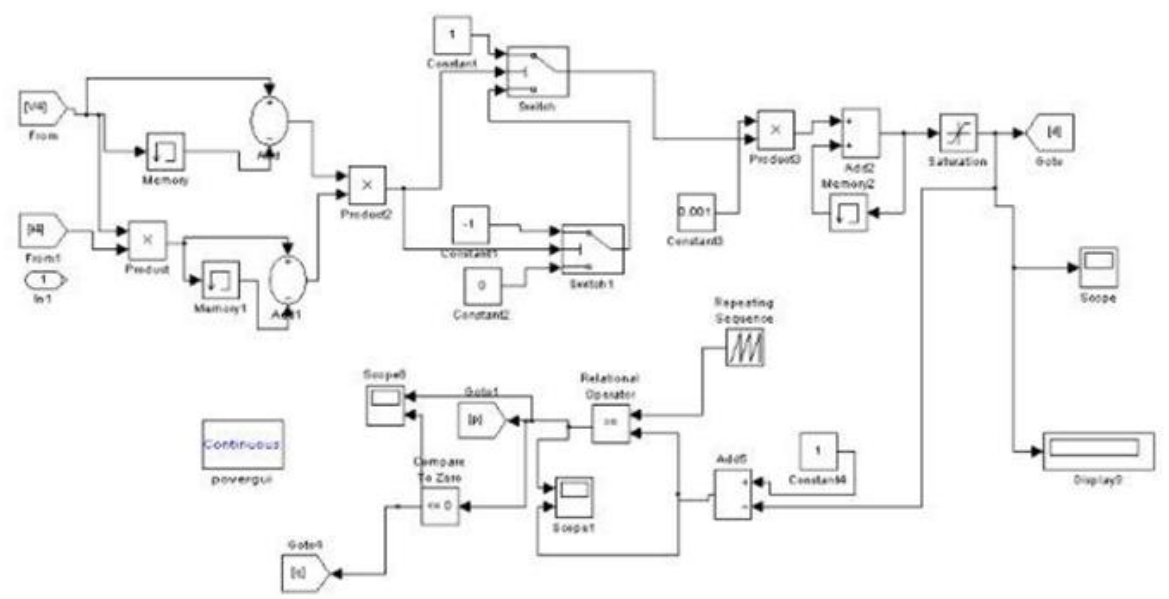

Fig 8 : Simulation Circuit of MPPT system

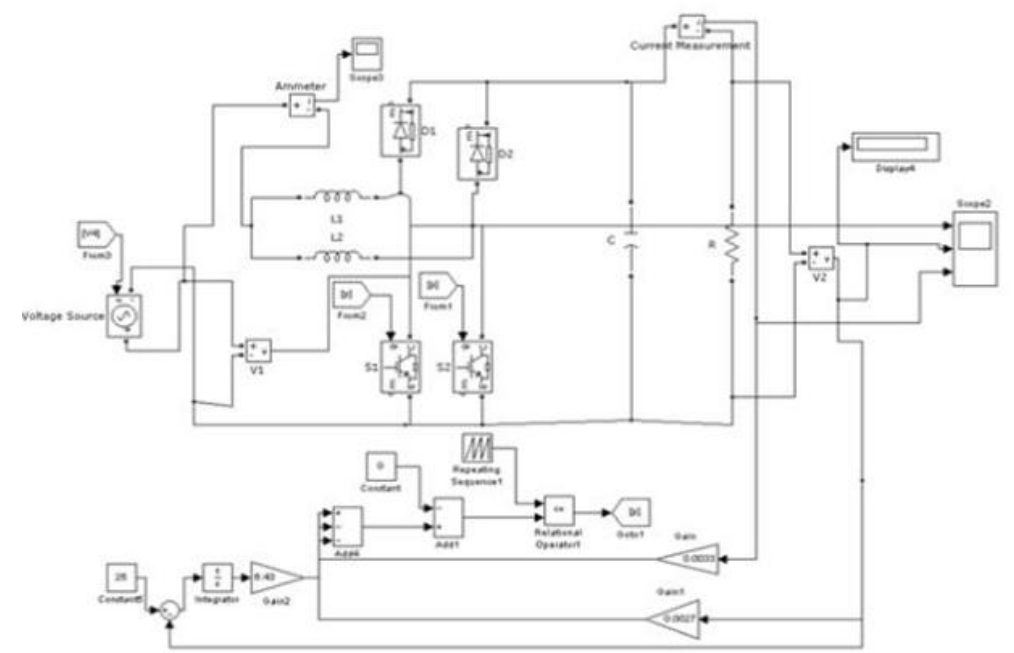

Fig 9 : Simulation Circuit of IBC converter
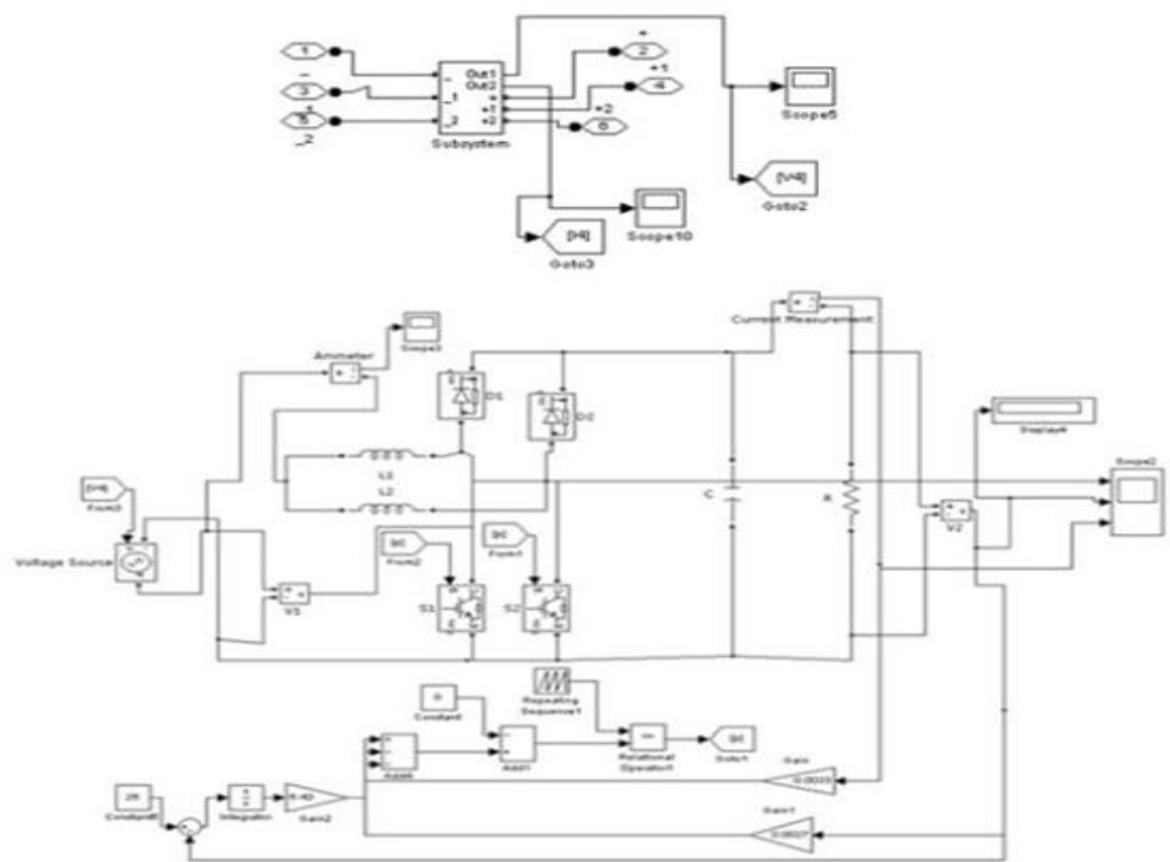

Fig 10 : Simulation circuit of PV cell model without MPP 


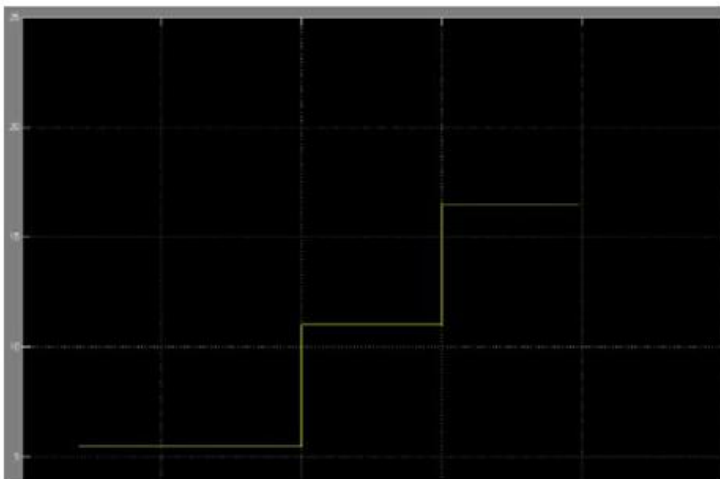

Fig 11. Varied input voltage signal
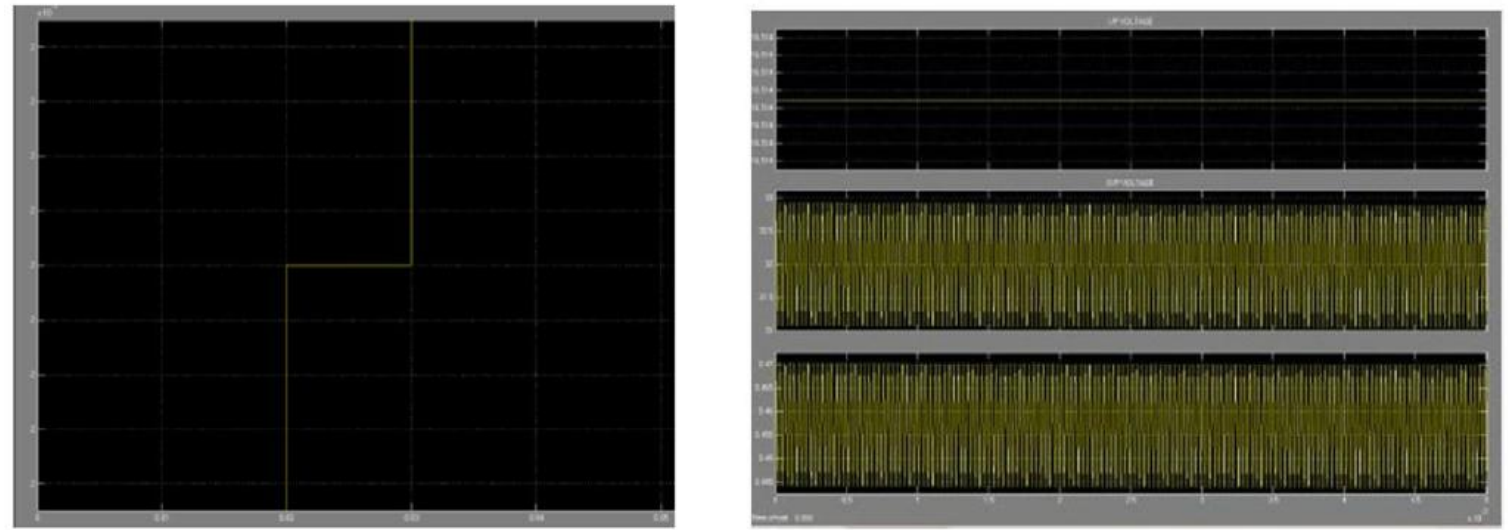

Fig 13. MPPT detection point during Fig 14. Voltage and current with MPPT Change in input signal

\section{Comparission Between Load Voltage And Power With Mppt And Without Mppt Circuit}

\begin{tabular}{|c|c|c|}
\hline & WITHOUT MPPT & WITH MPPT \\
\hline $\begin{array}{c}\text { OUTPUT } \\
\text { VOLTAGE }\end{array}$ & $26 \mathrm{~V}$ & $32 \mathrm{~V}$ \\
\hline $\begin{array}{c}\text { OUTPUT } \\
\text { POWER }\end{array}$ & $9.62 \mathrm{~W}$ & $14.2 \mathrm{~W}$ \\
\hline
\end{tabular}

\section{Conclusion}

The low power output from the PV panel is harnessed and boosted to drive the load. The MPPT circuit helps to increase the efficiency of conversion and also the control circuit gives the constant and desired voltage to the load side as per the requirement. The results obtained are tabulated and we can conclude MPPT circuit enhances the PV cell conversion capabilities and improves the overall efficiency of the system.

\section{Reference}

[1]. "Ultra-Large Gain Step-Up Switched-Capacitor DC-DC Converter With Coupled Inductor for Alternative Sources of Energy", Tsollg-Juu Liang, Shih-Ming Chen, Lung-Sheng Yang, Jian-Fuh Chen, and Adrian loinvici IEEE Transactions on Circuits and Systems-I: regular papers, VOL. 59, NO. 4, April,2012

[2]. "Light- Generated Effects on Power Switches Used in a PV Power System With Monolithically Embedded Power Converters, by Abusaleh M. Imtiaz, and Faisal H. Khan " IEEE JOUll1al of Photovoltaics,VOL.3,NO.IJanuary,2013.

[3]. Bin Gu, Jason Dominic, Jih-Sheng Lai, Zheng Zhao and Chuang Liu "High Boost Ratio Hybrid Transfonner DC-DC Converter for Photovoltaic Module Applications," IEEE Transactions on Power Electronics,VOL.28, NO.4, April,2013

[4]. Doo-Yong Jung, Young-Hyok Ji, Sang-Hoon Park, Yong-Chae Jung, and Chung-Yuen Won "Interleaved Soft-Switching Boost Convelter for Photovoltaic Power-Generation System," IEEE Transactions on Power Electronics, VOL. 26, NO. 4, April,2011

[5]. Photovoltaic MPPT Charge Controller", Amber Scheurer Ersuel Ago Juan Sebastian Hidalgo Steven Kobosko.

[6]. "DESIGN AND ANALYSIS OF INTERLEAVED BOOST CONVERTER FOR PHOTOVOLTAIC MODULE", International Journal of Power Control and Computation (IJPCSC) Vol5.No.2 2013 pp 34-41. 
[7]. “A High Efficient Improved Soft Switched Interleaved Boost Converter", International Journal of Engineering Trends and Technology (IJETT) - Volume4 Issue6- June 2013.

[8]. "An Interleaved Boost Converter with LC Coupled Soft Switching", International Journal of Recent Trends in Electrical \& Electronics Engg., Dec. 2013

[9]. Pradeep S V, P.Usha, "Implementation of P\&O Algorithm in MPPT Controlled Inverse Sepic Converter for Low Power Applications", International Journal of Latest Technology In Engineering, Management \& Applied Science-(IJLTEMAS ), ISSN 2278- 2540, Volume III, Issue VII, July 2014. 